\title{
100-YEAR-OLD HAEMATOLOGICA IMAGES: THE LONG ROAD FROM THE BEAUTY OF DRAWING TO THE OBJECTIVITY OF PHOTOGRAPHY
}

\section{Carlo L. Balduini}

Ferrata-Storti Foundation, Pavia, Italy

E-mail: CARLO L.BALDUINI - carlo.balduini@unipv.it

doi:10.3324/haematol.2020.261818

T he first apparatuses for taking pictures under the microscope were developed in the late 19th century. The Ernst Leitz's company catalog from 1899 included an instrument for "projecting microscopic objects and taking photo-micrographs", ${ }^{1}$ but the images obtained from these bulky devices were in gray scale and of very low quality. For a substantial improvement in the field of microphotography we had to wait until 1935, when the Kodak company launched the first multilayer photographic film that was capable of providing detailed color images. So, at the time of the birth of Haematologica in 1920, the only way to reproduce color images of cells and tissues seen under a microscope was to rely exclusively on the skill of specialized artists who could draw them. The images reproduced on the covers of the previous issues of Haematologica testify to the extraordinary ability of these artists. However, a drawing has a large margin of subjectivity and it is only the credibility of the author that testifies to its accuracy. To overcome this limit, starting in the 1930s, papers began to appear in Haematologica which reported gray scale, low resolution photographic images associated with a color drawing of the same microscopic field. With this approach, the authors intended to combine the objectivity of photography with the ability of the designed plates to reproduce the smallest details. It was the end of an era, and a new one began.

The cover image of this issue of Haematologica was created by juxtaposing the photographic image of a cytological preparation alongside the image of the same microscopic field drawn by hand. The original images are shown in Figure 1. They were taken from an article published in Haematologica in 1936 by Edoardo Storti, ${ }^{2}$ a pupil of Adolfo Ferrata and, decades later, one of the most active Editors of Haematologica. In the article, Storti reported on a patient with acute erythremic myelosis (now known as pure erythroid leukemia), thus providing further confirmation of the existence of this disease, described for the first time in Haematologica by Giovanni Di Guglielmo in 1928. ${ }^{3,4}$

\section{References}

1. Leitz E, ed. Catalogue No 38: Microscopes and Accessory Apparatus. Wetzlar, Germany: Ernst Leitz; 1899

2. Storti E. [Contributo allo studio della mielosi eritemica]. Haematologica. 1936;17:393-460.

3. Di Guglielmo G. [Le eritremie]. Haematologica. 1928;9:301-347.

4. Balduini CL. 100-Year Old Haematologica Images: Di Guglielmo Disease or Pure Erythroid Leukemia. Haematologica. 2020;105(3):525
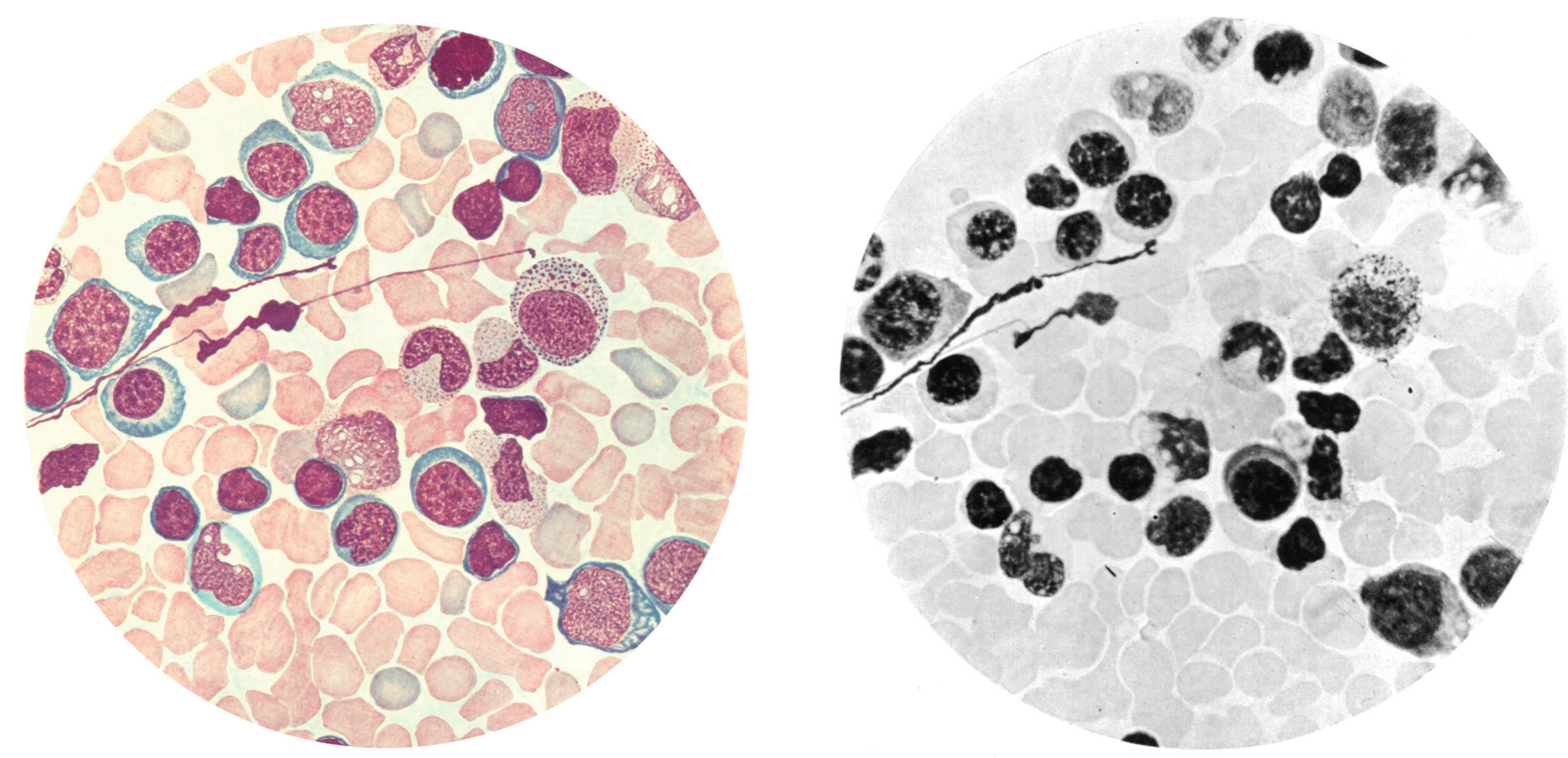

Figure 1. Peripheral blood (buffy coat smear) of a patient with acute erythremic myelosis. These images have been taken from an article published in Haematologica by Edoardo Storti in $1936^{2}$ and the photo in gray scale was used to testify the genuineness of the color drawing. 